\title{
Trehalose Synthesis Contributes to Osmotic Stress Tolerance and Virulence of the Bacterial Wilt Pathogen Ralstonia solanacearum
}

\author{
April M. MacIntyre', John X. Barth'1, Molly C. Pellitteri Hahn², Cameron O. Scarlett' ${ }^{2}$, Stéphane Genin ${ }^{3}$, \\ and Caitilyn Allen ${ }^{1,+}$ \\ ${ }^{1}$ Department of Plant Pathology, University of Wisconsin-Madison, U.S.A. \\ ${ }^{2}$ Analytical Instrumentation Center, School of Pharmacy, University of Wisconsin-Madison \\ ${ }^{3}$ LIPM, Université de Toulouse, INRAE, CNRS, Castanet-Tolosan, France
}

Accepted 21 November 2019.

\begin{abstract}
The xylem-dwelling plant pathogen Ralstonia solanacearum changes the chemical composition of host xylem sap during bacterial wilt disease. The disaccharide trehalose, implicated in stress tolerance across all kingdoms of life, is enriched in sap from $R$. solanacearum-infected tomato plants. Trehalose in xylem sap could be synthesized by the bacterium, the plant, or both. To investigate the source and role of trehalose metabolism during wilt disease, we evaluated the effects of deleting the three trehalose synthesis pathways in the pathogen: TreYZ, TreS, and OtsAB, as well as its sole trehalase, TreA. A quadruple treY/treS/otsA/treA mutant produced 30-fold less intracellular trehalose than the wild-type strain missing the trehalase enzyme. This trehalose-nonproducing mutant had reduced tolerance to osmotic stress, which the bacterium likely experiences in plant xylem vessels. Following naturalistic soilsoak inoculation of tomato plants, this triple mutant did not cause disease as well as wild-type $R$. solanacearum. Further, the wild-type strain out-competed the trehalose-nonproducing mutant by over 600-fold when tomato plants were coinoculated with both strains, showing that trehalose biosynthesis helps $\boldsymbol{R}$. solanacearum overcome environmental stresses during infection. An ots $A$ (trehalose-6-phosphate synthase) single mutant behaved similarly to $\Delta$ treY/treS/ots $A$ in all experimental settings, suggesting that the OtsAB pathway is the dominant trehalose synthesis pathway in $R$. solanacearum.
\end{abstract}

Keywords: bacterial wilt, drought stress, metabolism, Ralstonia solanacearum, salt stress, tomato, trehalose, vascular wilt, xylem metabolome

Trehalose synthesis is necessary for full fitness and virulence of Ralstonia solanacearum, a high-impact crop pathogen with

${ }^{\dagger}$ Corresponding author: C. Allen; callen@wisc.edu

Funding: This research was supported by a United States Department of Agriculture National Institute of Food and Agriculture Predoctoral Fellowship to A. M. MacIntyre (2018-67011-27999) and by the University of Wisconsin-Madison College of Agricultural and Life Sciences.

*The $\boldsymbol{e}$-Xtra logo stands for "electronic extra" and indicates a supplementary figures file is published online.

The author(s) declare no conflict of interest.

(c) 2020 The American Phytopathological Society an unusually broad host range. We created single and triple bacterial mutants missing one or all three trehalose synthetic pathways and assessed their fitness in vitro and in planta. Our data establish a role for the widely conserved prokaryotic OtsA/B metabolic pathway in both osmotic stress tolerance and for mediating $R$. solanacearum success in planta during bacterial wilt disease, further contributing to the growing evidence that trehalose plays key roles in host-pathogen interactions. Examining $R$. solanacearum trehalose biology under abiotic stress and inside the plant host elucidated a previously uncharacterized metabolic virulence strategy.

Ralstonia solanacearum is an economically damaging plant pathogen that causes bacterial wilt disease in over 200 plant species worldwide (Elphinstone 2005; Hayward 1991). $R$. solanacearum is difficult to eradicate because it can survive for long periods of time in soil, water, and tolerant hosts (Álvarez et al 2010; Denny 2006). R. solanacearum enters host roots through natural openings or wounds and migrates to the xylem to disseminate through the rest of the plant (Yao and Allen 2006; Tans-Kersten et al. 2001; Vasse et al. 1995; Huang and Allen 1997, 2000; Tran et al. 2016). In the xylem, $R$. solanacearum forms biofilms, produces large amounts of extracellular polymeric substances (EPS), and proliferates to $>10^{9}$ CFU per gram of stem tissue (Tran et al. 2016; Mori et al. 2016; Orgambide et al. 1991). The abundant EPS and large bacterial populations block xylem vessels and disrupt water flow, leading to host plant wilting and death.

How $R$. solanacearum grows to such high cell densities in xylem sap, historically classified as a nutrient-poor environment, remains a mystery (Bialczyk et al. 2004; Lowe-Power et al. 2018b). Untargeted gas chromatography (GC) time of flight mass (MS) metabolomic analysis revealed that xylem sap from healthy plants and $R$. solanacearum-infected plants contain different amounts and types of metabolites (LowePower et al. 2018a). Further, $R$. solanacearum grew better in ex vivo xylem sap harvested from infected plants than it did in sap from healthy plants, suggesting that $R$. solanacearum manipulates its host niche in ways that optimize its fitness. The nonreducing disaccharide trehalose was among the several hundred metabolites enriched in xylem sap from infected plants. The 19.39-fold greater levels of trehalose in sap from wilting plants led us to hypothesize that it plays a role in bacterial wilt disease.

Trehalose is a well-known player in biological stress responses, signaling, development, and metabolic regulation (Avonce et al. 2006; Iturriaga et al. 2009; Lunn et al. 2014; Paul

462 / Molecular Plant-Microbe Interactions 
et al. 2008). Composed of glucose and UDP-glucose, this nonreducing sugar can accumulate to high levels in cells and act as a molecular chaperone, replacing water and stabilizing membranes in desiccated environments. Trehalose metabolism contributes to plant abiotic stress tolerance by several known and unknown mechanisms (Avonce et al. 2004; Iordachescu and Imai 2008). On the organismal level, it has many more functions. Trehalose and the related metabolite trehalose-6phosphate (T6P) both play major roles in plant development and signaling. T6P is an indicator of sucrose levels that helps plants optimize their sucrose-to-starch ratio (Kolbe et al. 2005; Lunn et al. 2006, 2014). All plants encode pathways to synthesize trehalose, and a highly conserved trehalase enzyme that breaks down trehalose (Paul et al. 2008). Plants make trehalose using the trehalose-P phosphatase (TPP) pathway, in which TPS converts UDP-glucose and glucose to T6P, then T6P phosphatase dephosphorylates T6P to produce trehalose. The enzymes in the TPP pathway are homologous to the bacterial OtsA/OtsB pathway and use the same substrates. However, prokaryotes have evolved several additional trehalose synthesis pathways. Bacterial trehalose metabolism contributes to tolerance of heat, cold, oxidative, and osmotic stresses and is an important membrane component in some Mycobacterium species (Benaroudj et al. 2001; Kandror et al. 2002; Murphy et al. 2005; Reina-Bueno et al. 2012; Sleator and Hill 2002). Trehalose biosynthesis is also necessary for virulence of some bacterial pathogens and has been an antibiotic target (Tournu et al. 2013).

Despite exhaustive evidence of the biological benefits of trehalose, relatively little is known about how trehalose and related metabolites function during plant-microbe interactions. Mutating the treS and tre $Y / Z$ pathways in the tomato leaf pathogen Pseudomonas syringae pv. syringae decreased bacterial phyllosphere fitness and tolerance of salt stress (Freeman et al. 2010). In a citrus canker model, mutating the Xanthomonas citri ots $A / B$ trehalose synthesis pathway reduced virulence, and spraying exogenous trehalose on citrus leaves triggered plant defense responses (Piazza et al. 2015). Similarly, exogenous application of $30 \mathrm{mM}$ trehalose to Arabidopsis also triggered expression of defense-response genes (Bae et al. 2005). In an aphid, Arabidopsis, and tomato model system, increasing trehalose levels deterred aphid feeding, possibly because elevated trehalose levels promote accumulation of starch instead of sucrose (Singh and Shah 2012; Singh et al. 2011). The opportunistic pathogen Pseudomonas aeruginosa needed its $t r e Y / Z$ and treS pathways to cause full symptoms on Arabidopsis; this defect was rescued in plants missing certain cell-wall components or by application of trehalose or ammonium nitrate, suggesting trehalose metabolism is required for bacterial movement into intracellular spaces and nitrogen uptake (Djonović et al. 2013).

Some observations hint that trehalose plays a role in bacterial wilt disease. $R$. solanacearum expresses genes for all its predicted trehalose metabolic pathways during tomato pathogenesis (Fig. 1) (Jacobs et al. 2012). Additionally, during bacterial wilt disease, the $R$. solanacearum periplasmic trehalase (TreA), which breaks down trehalose into two glucoses, is highly expressed at high cell densities by the global virulence regulator PhcA (Jacobs et al. 2012; Khokhani et al. 2017). Finally, with the exception of phylotype IV (Indonesian) strains, genomes of all sequenced $R$. solanacearum strains encode RipTPS, a type III-secreted effector that is a functional TPS and a duplicate of OtsA (Poueymiro et al. 2014). As is common for single effector mutants, deleting this effector had no detectable effect on virulence or competitive fitness in Arabidopsis, tomato, or eggplant, but its existence suggests a role in pathogenesis (Poueymiro and Genin 2009).
To determine the role or roles of $R$. solanacearum trehalose synthesis in pathogen fitness and virulence, we mutated all three apparent pathways for synthesis of trehalose in the wellstudied $R$. solanacearum GMI1000 strain. The responses of these mutants to abiotic stressors and to conditions in planta indicated that the trehalose synthesis contributes to osmotic stress tolerance in vitro and to fitness and virulence in tomato host plants. Moreover, we found that the OtsA/OtsB pathway is the predominant pathway for trehalose synthesis in GMI1000.

\section{RESULTS}

Genetic basis of trehalose metabolism.

BLAST analysis of bacterial pathways to synthesize trehalose indicated that the genome of $R$. solanacearum GMI1000 encodes three potential pathways to synthesize trehalose and one pathway to degrade it. Figure 1 provides details on pathways, gene locus tags, expression levels, and enzymatic reactions. Briefly, the OtsA/B pathway combines G6P and UDP-glucose into T6P using TPS. Trehalose-6-phosphatase then removes the phosphate group to yield trehalose. The TreY/Z pathway reversibly converts trehalose from maltooligosaccharides. TreS converts maltose into trehalose in a single step. TreA is a glycoside hydrolase that cleaves trehalose into two glucose molecules in a one-step reaction. The gene for trehalase (treA) is absent from strains in the cool-tolerant potato brown rot subgroup (known historically as race 3 biovar 2), but all the publicly available $R$. solanacearum species complex genomes sequenced to date encode OstA/B, TreY/Z, and TreS, meaning these three trehalose biosynthesis pathways are part of the $R$. solanacearum core genome. Two additional prokaryotic trehalose synthesis pathways, TreT and TreP, are not present in $R$. solanacearum.

We targeted all four $R$. solanacearum trehalose metabolic pathways for mutagenesis (Table 1). The $\Delta$ treA mutant could not grow in minimal media with trehalose as a sole carbon source, validating that this gene encodes a functional trehalase (data not shown). In Pseudomonas stuzteri, TreS can also break down trehalose, but this does not occur in $R$. solanacearum, since mutating tre $A$ was sufficient to prevent $R$. solanacearum from growing on trehalose as a sole carbon source (Lee et al. 2005). Quantitative PCR measurement of tre $Y$, treS, and ots A expression in a treA mutant background showed that mutating trehalase did not affect expression of any of the trehalose biosynthetic pathways, suggesting trehalose synthesis is regulated independently from its degradation (data not shown). Further characterization of the $\triangle t r e A$ mutant is reported elsewhere (Hamilton et al. 2019). The $\Delta$ otsA and $\Delta$ treY/treS/otsA strains grew as well as wild type in minimal media plus glucose at the $R$. solanacearum optimal growth temperature of $28^{\circ} \mathrm{C}$ (Fig. $2 \mathrm{~A})$. Initial in vitro and in planta assays revealed that the $\Delta$ tre $Y$ and $\Delta$ tre $S$ single mutants behaved indistinguishably from wildtype $R$. solanacearum (data not shown), so subsequent studies focused on the $\Delta$ otsA and $\Delta$ treY/treS/otsA strains.

\section{The $\Delta$ ots $A$ and $\Delta$ treY/treS/otsA strains make little to no trehalose.}

To confirm that $\Delta$ otsA and $\Delta$ treY/treS/otsA strains lacked the ability to synthesize trehalose, we used liquid chromatography tandem MS (LC-MS/MS) to quantify trehalose in $R$. solanacearum cell lysate and spent culture media. Initial studies indicated that trehalose was degraded by endogenous trehalase during sample preparation, so we deleted treA from the biosynthetic mutants to create $\Delta$ otsA/treA and $\Delta$ treY/treS/otsA/treA polymutants. Cell lysates obtained after sonicating trehalose metabolic mutant cells contained 30-fold less trehalose than lysates of $R$. solanacearum with intact trehalose synthetic pathways (one-way analysis 
of variance [ANOVA], $P<0.0001)$, with GMI1000- $\Delta$ treA producing $1.36 \mathrm{ng}$ of trehalose per gram of bacteria $(\mathrm{ng} / \mathrm{g})$, GMI1000- $\Delta$ otsA/treA producing $0.053 \mathrm{ng} / \mathrm{g}$, and GMI1000 $\Delta$ treY/treS/otsA/treA producing $0.06 \mathrm{ng} / \mathrm{g}$. Trehalose levels in $\triangle$ otsA/treA and $\Delta$ treY/treS/otsA/treA did not differ from each other. No trehalose was detected in spent cell media, suggesting that $R$. solanacearum does not export trehalose.

\section{$R$. solanacearum does not require trehalose synthesis for tolerance of chronic and acute temperature stress, oxidative stress, desiccation stress, or for biofilm formation in vitro.}

In prokaryotes, the ability to synthesize and accumulate trehalose is often associated with tolerance of diverse abiotic stressors, so we evaluated the fitness of the trehalose metabolic mutants responding to heat, cold, oxidative, and desiccation stress. The $\Delta$ otsA and $\Delta$ treY/treS/otsA mutants grew as well as wild-type $R$. solanacearum at the stressfully high temperature of $37^{\circ} \mathrm{C}$ and at the stressfully low temperature of $20^{\circ} \mathrm{C}$ (Fig. $2 \mathrm{~A}$ and $\mathrm{B})$. Trehalose metabolism was similarly not required for survival of 45,46 , and $47^{\circ} \mathrm{C}$ heat shocks; indeed, the $\Delta$ treY/treS/otsA strains recovered from a $47^{\circ} \mathrm{C}$ heat shock slightly better than wild type (Fig. 2C). Exposure to sublethal doses of the oxidative chemical paraquat had similar effects on growth of wild type, $\Delta$ otsA, and $\Delta$ treY/treS/otsA strains (Fig. 2D). The $\Delta$ ots $A$ and $\Delta$ treY/treS/otsA mutants recovered as well as wild type from desiccation under airflow (Fig. 2E). Finally, although some bacteria need trehalose metabolism to form biofilms, trehalose biosynthesis was not required for $R$. solanacearum biofilm formation in an in-vitro polyvinyl chloride (PVC) plate assay (Fig. 2F).

We also assessed the ability of the trehalose metabolic mutants to tolerate stressful environmental conditions that $R$. solanacearum might encounter in the field. Trehalose metabolism did not contribute to long-term survival of $R$. solanacearum in soil at $28^{\circ} \mathrm{C}$ after it had escaped from

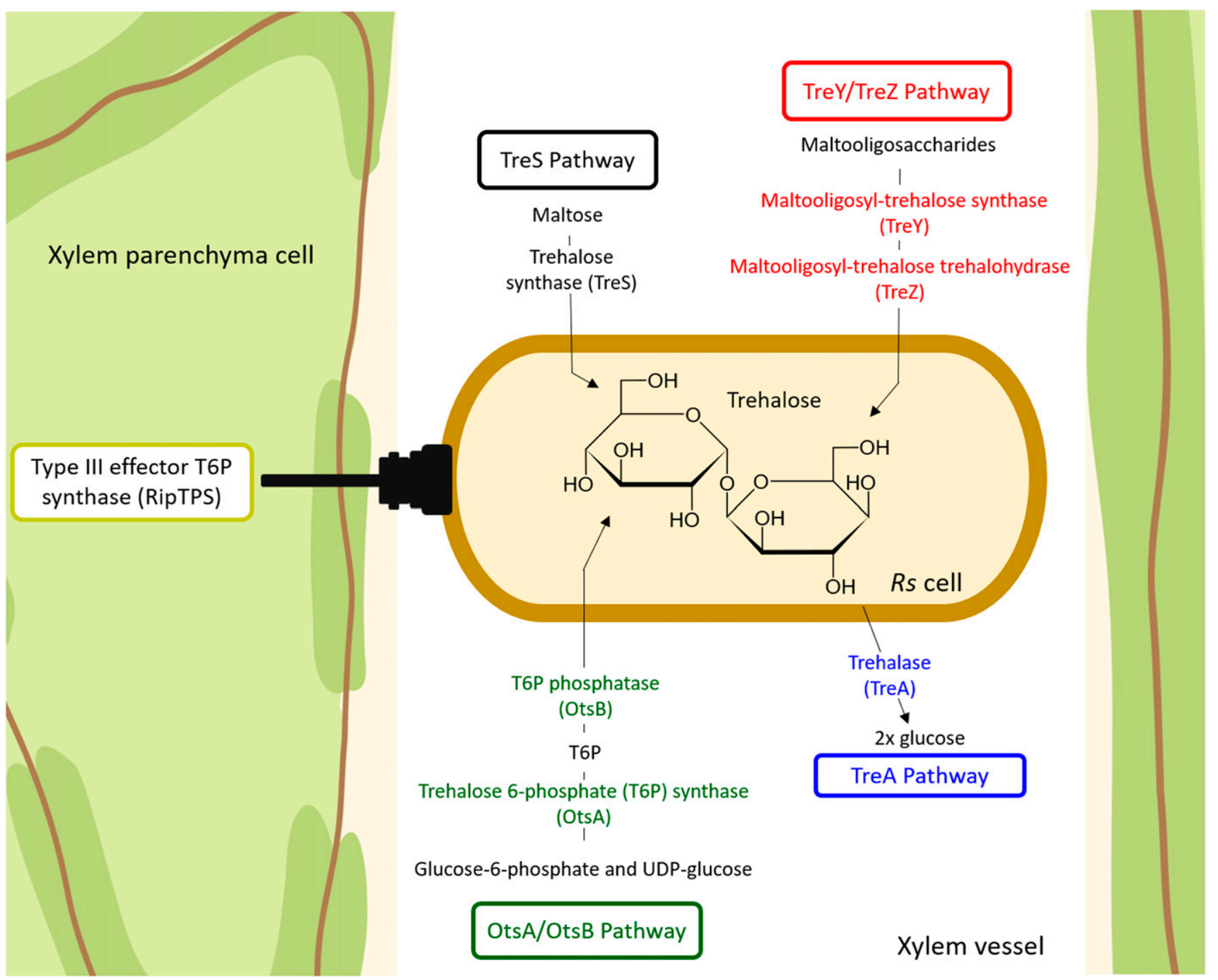

Fig. 1. Ralstonia solanacearum GMI1000 pathways to synthesize and degrade trehalose. Gene names, locus tags (LT), and absolute expression (AE) values in planta (AE > 7 is considered expressed) are listed below for each enzyme (Jacobs et al. 2012). The OtsA/B pathway converts glucose-6-phosphate and UDPglucose into trehalose-6-phosphate (T6P) using T6P synthase (otsA, LT: Rsp1105, AE: 9.88). Trehalose-6-phosphatase (otsB, LT: Rsp1104, AE: 7.41) then removes the phosphate group to yield trehalose. The TreY/Z pathway reversibly converts trehalose from maltooligosaccharides via a two-step reaction. Maltooligosyl-trehalose synthase (treY, LT: Rsp0235, AE: 7.41) flips the glycosidic bond on a maltose at the end of an oligosaccharide chain and maltooligosyltrehalose trehalohydrase (treZ, LT: Rsp0237, AE: 8.63) hydrolyzes the trehalose from the end of the chain. TreS converts maltose into trehalose in a single step (treS, LT: Rsp0240, AE: 8.17). The periplasmic trehalase (treA, LT: Rsp0277, AE: 12.53), which degrades trehalose into two glucoses via a single-step reaction, is activated at high cell densities by the global virulence regulator PhcA (Khokhani et al. 2017). RipTPS (LT: Rsp0731, AE: 7.35) is a T6P and a type III effector injected by $R$. solanacearum into plant cells (Poueymiro et al. 2014). 
infected tomato plants (Supplementary Fig. 1A). Further, trehalose metabolism did not affect $R$. solanacearum survival in potato mini tubers at the typical tuber storage temperature of $4^{\circ} \mathrm{C}$ or in water at $4^{\circ} \mathrm{C}$ (Supplementary Fig. 1B and $\mathrm{C}$ ).

\section{R. solanacearum TPS contributes \\ to osmotic stress tolerance.}

To determine if trehalose biosynthesis contributes to ionic and nonionic osmotic stress tolerance in $R$. solanacearum, we measured growth of $\Delta$ otsA and $\Delta$ treY/treS/otsA in rich media supplemented with either $0.15 \mathrm{M}$ sodium chloride (ionic osmotic stress) or $15 \%$ polyethylene glycol 4000 (nonionic osmotic stress). There was no difference between $\Delta o t s A$ and $\Delta$ treY/treS/otsA with respect to tolerance of either osmotic stress. However, both mutants grew significantly less well than wild type under these conditions. These small but highly replicable differences demonstrate that $R$. solanacearum needs trehalose synthesis for full osmotic stress tolerance (Fig. 3A and $\mathrm{B})$.

TPS synthesis is required for full virulence and fitness.

To assess the role of trehalose biosynthesis in a representative biological context, we measured fitness and virulence of the trehalose metabolic mutants during infection of a natural host, tomato. Both the $\triangle$ otsA and $\Delta$ treY/treS/otsA mutant strains were significantly less virulent than wild-type strain GMI1000 following a naturalistic soil-soak inoculation of unwounded tomato plants (Fig. 4A, two-way repeated measures ANOVA, wild type versus $\triangle$ otsA, $P<0.001$, wild type versus $\Delta$ treY/treS/otsA, $P<0.01, \Delta$ ots A versus $\Delta$ treY/treS/ots $A, P<$ $0.05)$. To determine if this virulence defect resulted from delayed host colonization, we compared population sizes of wild-type and mutant strains in the midstems of tomato plants 5 days after soil-soak inoculation. At this timepoint, plants inoculated with the $\Delta$ otsA mutant contained smaller bacterial

Table 1. Strains, plasmids, and primers used in this study

\begin{tabular}{|c|c|c|}
\hline Strain & Description $^{\mathbf{a}}$ & Reference \\
\hline GMI1000 & $\begin{array}{l}\text { Ralstonia solanacearum phylotype } 1 \text { sequevar } 18, \\
\text { isolated from tomato in French Guyana }\end{array}$ & Boucher et al. 1985 \\
\hline GMI1000-kan & $\begin{array}{l}\text { GMI1000 with pRCK-GWY integrated into chromosome, } \\
\text { used for competition assays; } \operatorname{Kan}^{\mathrm{R}}\end{array}$ & Lowe-Power et al. 2016 \\
\hline$\triangle o t s A$ & $\begin{array}{l}\text { GMI1000 Rsp1105 trehalose-6-phosphate synthase replaced } \\
\text { in frame with a gentamicin resistance cassette; } \mathrm{Gm}^{\mathrm{R}}\end{array}$ & $\begin{array}{l}\text { Recreated by } \mathrm{S} \text {. Genin for this study } \\
\text { via natural transformation }\end{array}$ \\
\hline$\Delta t r e Y$ & $\begin{array}{l}\text { Unmarked in-frame GMI1000 Rsp0235 deletion mutant; } \\
\text { Rsp0235 annotated as a putative maltooligosyl } \\
\text { trehalose synthase transmembrane protein }\end{array}$ & This study \\
\hline$\Delta$ treS & $\begin{array}{l}\text { Unmarked in-frame GMI1000 Rsp0240 deletion mutant; } \\
\text { Rsp0240 annotated as a putative trehalose synthase, } \\
\text { maltose alpha-D-glucosyltransferase }\end{array}$ & This study \\
\hline$\Delta t r e A$ & $\begin{array}{l}\text { GMI1000 Rsp0277 mutant missing trehalase enzyme. } \\
\text { Gene replaced via homologous recombination with } \\
\text { streptomycin/spectinomycin resistance cassette; } \\
\text { Strep }^{\mathrm{R}} \mathrm{Sm}^{\mathrm{R}}\end{array}$ & This study \\
\hline$\Delta o t s A / t r e A$ & $\begin{array}{l}\text { GMI1000 mutant missing Rsp1105 and } \\
\text { Rsp0277; Gm }{ }^{\mathrm{R}} \operatorname{Strep}^{\mathrm{R}} \mathrm{Sm}^{\mathrm{R}}\end{array}$ & This study \\
\hline$\Delta$ treY/treS/otsA/treA & $\begin{array}{l}\text { GMI1000 mutant missing Rsp0235, Rsp1105, } \\
\text { Rsp0240, and Rsp0277; } \mathrm{Gm}^{\mathrm{R}} \mathrm{Sm}^{\mathrm{R}}\end{array}$ & This study \\
\hline$\Delta$ treY/treS & $\begin{array}{l}\text { Unmarked stacked GMI1000 mutant } \\
\text { missing Rsp0235 and Rsp0240 }\end{array}$ & This study \\
\hline$\Delta$ treY/treS/otsA & $\begin{array}{l}\text { Stacked GMI1000 mutant missing Rsp0235, } \\
\text { Rsp0240, and Rsp1105; } \mathrm{Gm}^{\mathrm{R}}\end{array}$ & This study \\
\hline \multicolumn{3}{|l|}{ Plasmids } \\
\hline pUFR80 & Positive selection ( $\mathrm{sacB}$ ) suicide vector; $\mathrm{Suc}^{\mathrm{S}}(\operatorname{sacB}), \mathrm{Kan}^{\mathrm{R}}$ & Castañeda et al. 2005 \\
\hline pUFR80-treS & $\begin{array}{l}\text { Vector used to generate unmarked } R \text {. solanacearum } \\
\Delta \text { treS mutant; } \operatorname{Suc}^{\mathrm{S}}(\operatorname{sacB}), \mathrm{Kan}^{\mathrm{R}}\end{array}$ & This study \\
\hline pUFR80-tre $Y$ & $\begin{array}{l}\text { Vector used to generate unmarked } R \text {. solanacearum } \\
\Delta \text { treY mutant; } \operatorname{Suc}^{\mathrm{S}}(\operatorname{sacB}), \operatorname{Kan}^{\mathrm{R}}\end{array}$ & This study \\
\hline pCR8 & $\begin{array}{l}\text { Vector containing spectinomycin/streptomycin } \\
\text { resistance cassette }\end{array}$ & Thermo-Fisher \\
\hline pST-Blue & Vector backbone for treA knockout mutant & Novagen \\
\hline pST-Blue-treA & Deletion construct for $\Delta$ treA knockout mutant & This study \\
\hline \multicolumn{3}{|l|}{ Cloning Primers ${ }^{\mathrm{b}}$} \\
\hline pUFR80 (hindIII)-treS UP F & 5'-aaaacgacggccagtgccaCCCAAGGTGATGTACCGGCT & This study \\
\hline pUFR80 (hindIII)-treS UP R & 5'-ccgaggtcacTCATGACGGTTGCTCCTCCGA & This study \\
\hline pUFR80 (hindIII)-treS DWN F & 5'-accgtcatgaGTGACCTCGGTCCATGACTTCG & This study \\
\hline pUFR80 (hindIII)-treS DWN R & 5'-agtcgacetgcaggcatgcaACGTACGGAATCAGCCGCTC & This study \\
\hline pUFR80 (hindIII)-treY UP F & 5'-taaacgacggccagtgccaTGGCGCTCGGTCTTGAGATAG & This study \\
\hline pUFR80 (hindIII)-treY UP R & 5'-cgccatgacgTTGGCAACACCCGCCGTA & This study \\
\hline pUFR80 (hindIII)-treY DWN F & 5'-gtgttgccaaCGTCATGGCGGGGAATCC & This study \\
\hline pUFR80 (hindIII)-treY DWN R & $5^{\prime}$-agtcgacctgcaggcatgcaTGTGGGTGATTCCCGACG & This study \\
\hline Blue-TreA UP & $5^{\prime}$-ttcgtgatatctgaattcgtcgacaGATCAGGAGCTTAGGCAG & This study \\
\hline Spec-TreA UP-R & 5'-gctatgaccatgtTGTTCTCCTGCGTTGGTC & This study \\
\hline TreA-spec-F & 5'-acgcaggagaacaACATGGTCATAGCTGTTTC & This study \\
\hline TreA down spec $\mathrm{R}$ & 5'-agagcggagtgacTAAGGGATTTTGGTCATGG & This study \\
\hline Spec TreA down & $5^{\prime}$-ccaaaatcccttaGTCACTCCGCTCTTACCTC & This study \\
\hline Blue treA down & 5'-gtctagagctagcetaggetcgagaACGTGTTCTTCTCGTCCAC & This study \\
\hline
\end{tabular}

${ }^{a} \mathrm{Sm}^{\mathrm{R}}=$ spectinomycin and streptomycin resistance, $\mathrm{Kan}^{\mathrm{R}}=$ kanamycin resistance, $\mathrm{Gm}^{\mathrm{R}}=$ gentamicin resistance.

${ }^{\mathrm{b}}$ Lowercase bases show the region that overlaps the adjacent fragment and uppercase bases indicate the region specific for the product of interest. 
A

Chronic heat

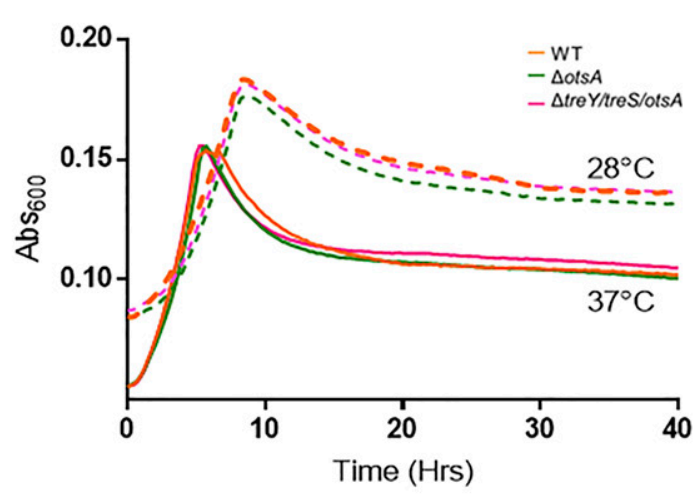

C

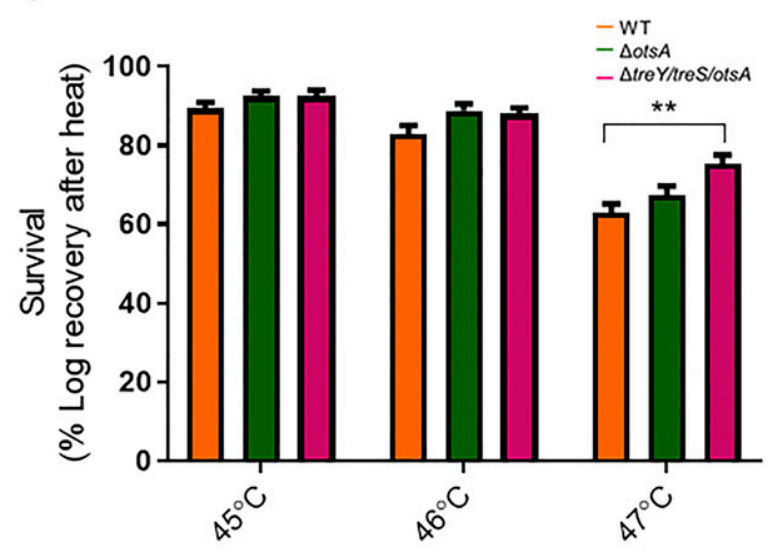

E

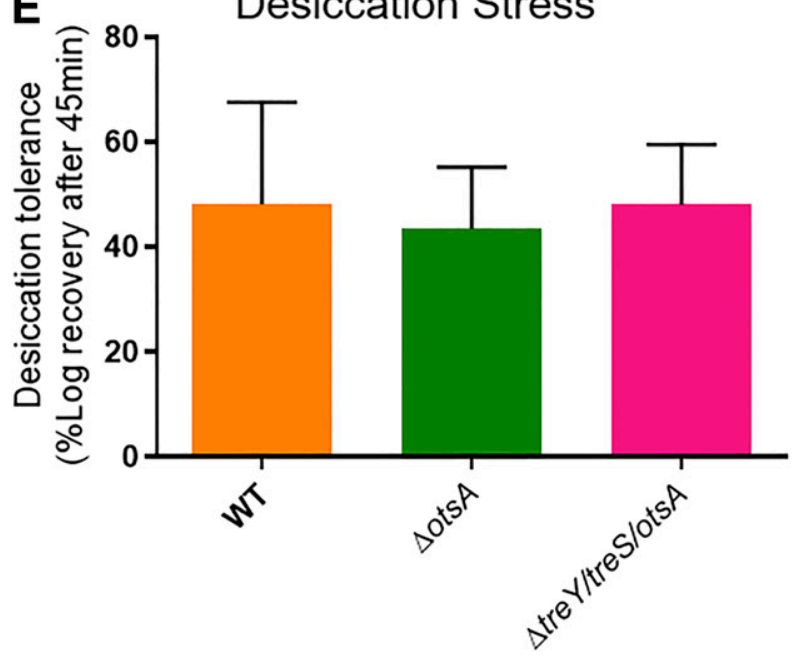

B
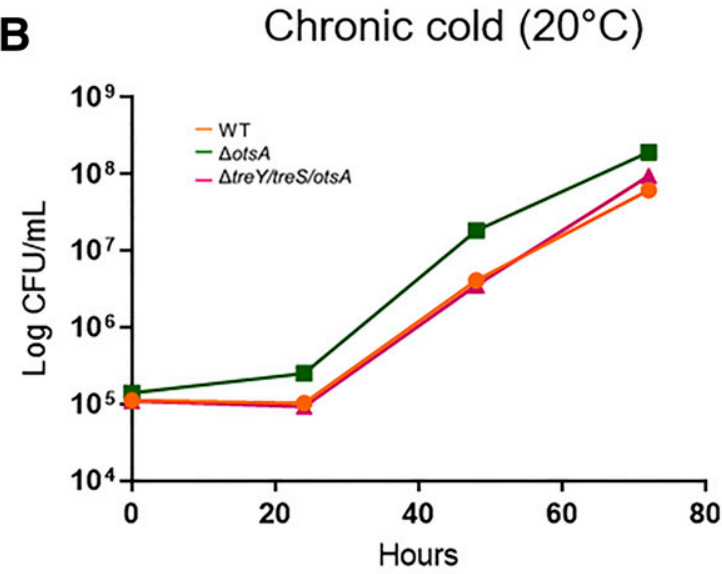

D

\section{Oxidative Stress}

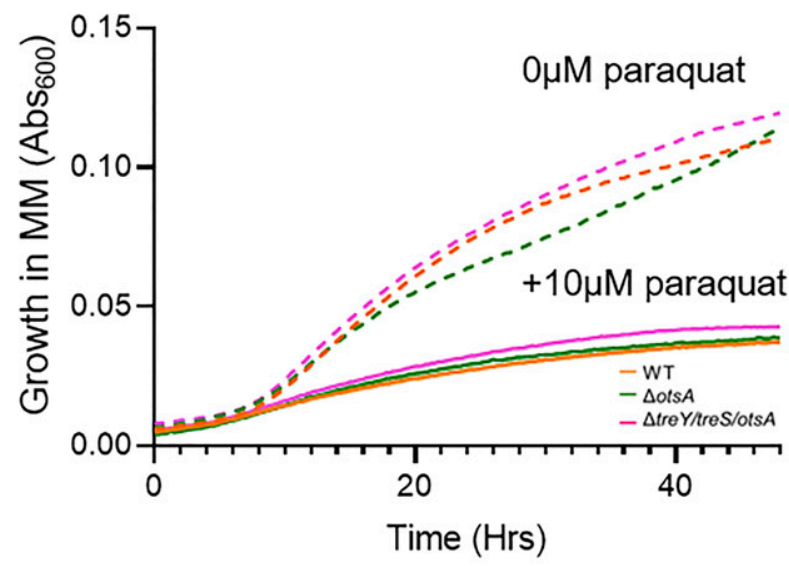

F
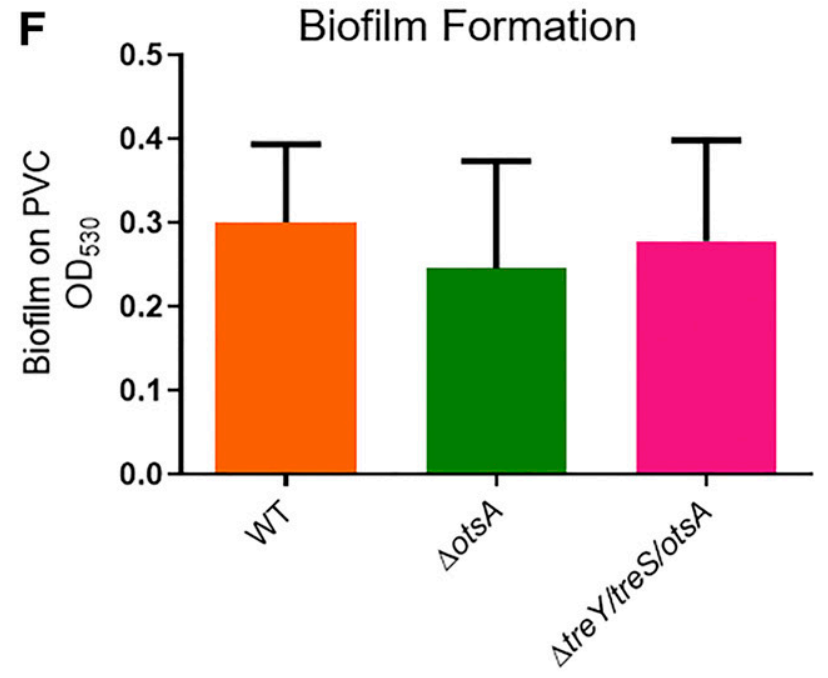

Fig. 2. Trehalose metabolism is not required for tolerance of chronic or acute temperature stress, desiccation, or in-vitro biofilm formation. A, Growth of wildtype Ralstonia solanacearum GMI1000 and trehalose biosynthetic mutants in Boucher's minimal medium (BMM) $+0.2 \%$ glucose at $28^{\circ} \mathrm{C}$ (optimal growth temperature) and $37^{\circ} \mathrm{C}$ did not differ (linear regression of growth curve slope, $P=.0728$ ). Symbols show means of three biological replicates of eight technical replicates each. B, Growth of wild-type $R$. solanacearum GMI1000 and trehalose biosynthetic mutants in $\mathrm{BMM}+0.2 \%$ glucose at $28^{\circ} \mathrm{C}$ and the suboptimal temperature of $20^{\circ} \mathrm{C}$ did not differ, as determined by dilution plating (linear regression of growth curve slope, $P=0.033$ ). Symbols show means of two biological replicates of four technical replicates each. C, Survival of $R$. solanacearum cells following 10-min heat treatment, as determined by serial dilution plating. There was no difference in survival among wild type, $\Delta$ ots $A$, and $\Delta$ treY/treS/otsA at 45 and $46^{\circ} \mathrm{C}$, but $\Delta$ treY/treS/otsA did recover slightly better than wild type at $47^{\circ} \mathrm{C}$ (Kruskal-Wallis test, multiple comparison with wild-type control, $P=0.0032$ ). Each column indicates mean of three biological replicates, each containing four technical replicates; bars indicate standard error of mean. D, Growth of R. solanacearum strains at $28^{\circ} \mathrm{C}$ in $\mathrm{BMM}+0.2 \%$ glucose with or without $10 \mu \mathrm{M}$ paraquat did not differ by strain (analysis of variance [ANOVA] of areas under curves for each biorep, $P=0.70$ ). Symbols show means of three biological replicates of four technical replicates each. E, Survival of $R$. solanacearum strains following desiccation on nitrocellulose filters and rehydration, as enumerated by serial dilution plating, did not differ by strain (Kruskal-Wallis test, $P=0.55$ ). Symbols show means of three biological replicates, each containing six technical replicates; bars indicate standard deviation. F, $R$. solanacearum biofilm formation on polyvinyl chloride plates, measured as crystal violet stain absorbance following $24 \mathrm{~h}$ of static incubation, did not differ between strains (ANOVA, $P=0.16$ ). Symbols show means of four biological replicates of eight technical replicates each; bars indicate standard deviation. 
populations, on average, than plants inoculated with wild-type $R$. solanacearum (Kruskal-Wallis/Dunn's multiple comparison, $P=0.02$ ), but the population sizes of $\Delta$ treY/treS/otsA were not significantly different from those of the wild type (Fig. 4B, $P=$ 0.46). Because we sampled just 5 days after soil inoculation and root infection is a stochastic process, many midstems contained no detectable bacteria. However, plants inoculated with the wild type were indeed more frequently colonized at this early timepoint; $R$. solanacearum was detectable in $36.8 \%$ of wildtype-inoculated plants but in only 17.7 and $25 \%$ of plants inoculated with $\triangle$ ots $A$ and $\Delta$ treY/treS/otsA, respectively. Consistent with our abiotic stress tolerance results, there was no difference between $\Delta$ otsA and the $\Delta$ treY/treS/otsA triple mutant with respect to colonization ability. Competition experiments often reveal important but subtle reductions in fitness, so we soil-soak inoculated plants with a 1:1 mixture of marked wildtype and mutant strains and quantified population sizes of the two competing strains in plant midstems $120 \mathrm{~h}$ later. Loss of the OtsA trehalose biosynthetic pathway reduced $R$. solanacearum competitive fitness by 301-fold, while wild-type $R$. solanacearum out-competed the $\Delta$ treY/treS/otsA triple mutant by 690 -fold (Fig. $4 C)$. The lower colonization rates of the mutant strains and their significantly reduced competitive fitness indices suggest that $R$. solanacearum must synthesize trehalose to effectively colonize plants and cause disease.

\section{DISCUSSION}

The ability to synthesize trehalose helps $R$. solanacearum tolerate osmotic stress, but not other stressors.

Trehalose functions as a compatible solute in prokaryotes by accumulating in intracellular spaces to an equilibrium at which water no longer moves out of the cell into high osmolarity environments (Csonka 1989). Accumulating trehalose likely helps $R$. solanacearum tolerate osmotically stressful conditions in planta and in the environment. Consistent with this function, we found that $R$. solanacearum mutants unable to synthesize trehalose suffered a small but replicable and significant growth defect in the presence of osmotic stress, whether it was ionic $(\mathrm{NaCl})$ or nonionic (high-molecular weight polyethylene glycol). This defect was the same for a $\Delta$ treY/treS/otsA triple mutant lacking all three trehalose biosynthetic pathways and for an $\triangle$ ots $A$ single mutant, suggesting that trehalose produced via the OstA/B pathway confers most or all osmoprotection. Compatible solutes like trehalose could help this waterborne pathogen survive in osmotically challenging environments such as brackish irrigation water or drying soil or plant debris (van Elsas et al. 2001).

Not all prokaryotes use OtsA/B to make osmoprotective trehalose. While the OtsA/B pathway confers higher osmotic stress tolerance to Escherichia coli, TreS and TreY/Z are the biologically relevant pathways for osmoprotection in $P$. syringae (Freeman et al. 2010; Purvis et al. 2005; Strom and Kaasen 1993). Although our results show trehalose is an important compatible solute for $R$. solanacearum osmotic stress tolerance, bioinformatic analysis suggests that strain GMI1000 can synthesize several additional osmolytes, including betaine, proline, and GABA (Kyoto Encyclopedia of Genes and Genomes [KEGG] Modules rso_M00555, rso_M00015, and rso_M00136). These compounds may help $R$. solanacearum survive other stressors and could explain why trehalose biosynthesis was not required for wild-type tolerance of heat, cold, and desiccation.

$R$. solanacearum experiences oxidative stress during plant infection, but although trehalose contributes to tolerance of reactive oxygen species (ROS) in other prokaryotes, loss of trehalose synthesis did not make $R$. solanacearum more sensitive to the oxidative chemical paraquat (Benaroudj et al. 2001; Flores-Cruz and Allen 2009). However, the bacterium has other ways to overcome the oxidative environment inside the plant. $R$. solanacearum genomes encode many ROS scavengers, including catalases and peroxidases. These genes are highly expressed during bacterial wilt disease and mutants lacking either the peroxidase Bcp or the oxidative stress regulator OxyR are less successful in planta (Flores-Cruz and Allen 2009; Jacobs et al. 2012).

As a critical first step in bacterial wilt disease pathogenesis, $R$. solanacearum must attach to host plant roots and form microcolonies in a process analogous to biofilm formation (Tran et al. 2016). R. solanacearum mutants with either poor or excessive root attachment are less fit (Dalsing and Allen 2014; Khokhani et al. 2017). However, although trehalose metabolism influences biofilm formation in some other prokaryotes, inability to synthesize trehalose did not affect $R$. solanacearum
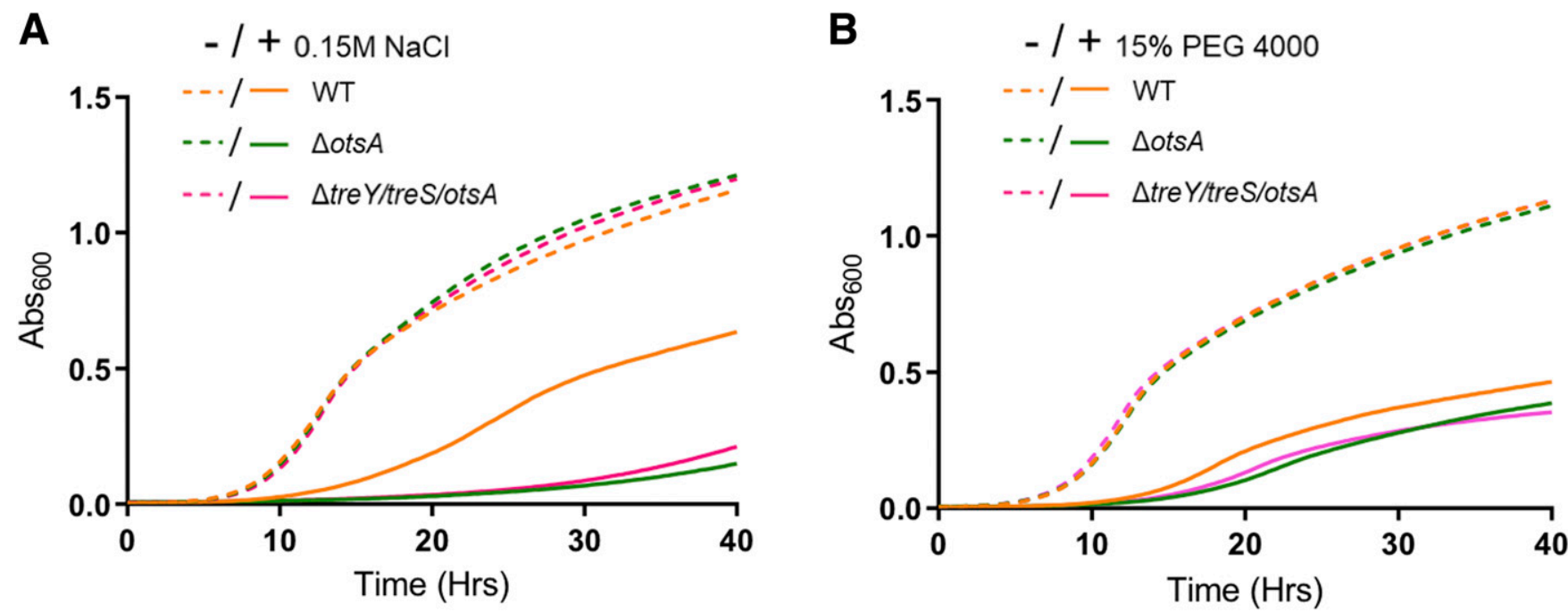

Fig. 3. Trehalose-6-phosphate synthase is required for wild-type osmotic stress tolerance. A, Ralstonia solanacearum cells were grown at $28^{\circ} \mathrm{C}$ for 48 h in casamino peptone agar rich broth supplemented or not with $0.15 \mathrm{M} \mathrm{NaCl}$ or $\mathbf{B}, 15 \%$ polyethylene glycol (PEG4000) dissolved in water. Growth curves show means of three experiments, each containing eight technical replicates per strain. Wild-type $R$. solanacearum grew better under both stresses than either $\triangle$ ots $A$, and $\Delta$ treY/treS/otsA mutants (two-way repeated measures analysis of variance, Tukey's multiple comparison test, $P<0.0001$ and $P<0.0001$, respectively). 
biofilm formation in the crystal violet-PVC plate assay $(\mathrm{Wu}$ et al. 2011). This in-vitro result suggested that the $\Delta$ otsA mutant is not deficient in biofilm formation, but we cannot rule out the possibility that trehalose affects biofilm formation in planta.

Soil temperature is a critical epidemiological variable for bacterial wilt disease development in the field. Under natural conditions $R$. solanacearum regularly encounters stressful temperature fluctuations and long periods in soil and water away from hosts (Álvarez et al 2010; Graham and Lloyd 1979; Hayward 1991). Although many prokaryotes require trehalose synthesis for tolerance of heat and cold and for environmental (phyllosphere) survival, in our experiments this trait did not contribute detectably to $R$. solanacearum response to chronic cold and heat stress in vitro or to longer-term survival in soil, water, or potato tubers (Freeman et al. 2010; Piazza et al. 2015). The $\Delta$ treY/treS/otsA triple mutant did recover slightly better than wild type from heat shock at $47^{\circ} \mathrm{C}$, but the $\triangle$ ots $A$ mutant did not, suggesting a possible role for tre $S$ or tre $Y$ in heat shock recovery. As a successful survivor and environmental scavenger, $R$. solanacearum has likely evolved other, possibly redundant, stress tolerance mechanisms that may involve the stress-responsive global metabolic regulators PhcA and EfpR (Khokhani et al. 2017; Hayward 1991; Perrier et al. 2018; Peyraud et al. 2016).

\section{Trehalose synthesis is required for full fitness and virulence.}

Trehalose synthesis likely contributes to $R$. solanacearum fitness during bacterial interactions with plants, since the OtsAB, TreYZ, and TreS pathways were not required for long-term environmental survival in water or in soil (Supplementary Fig. S1A and C). R. solanacearum trehalose biosynthetic mutants were significantly less virulent than wild type in a naturalistic assay that requires the bacterium to find and infect unwounded tomato roots from the soil, then overcome plant defenses to colonize host xylem, multiply, and spread into aboveground plant parts.

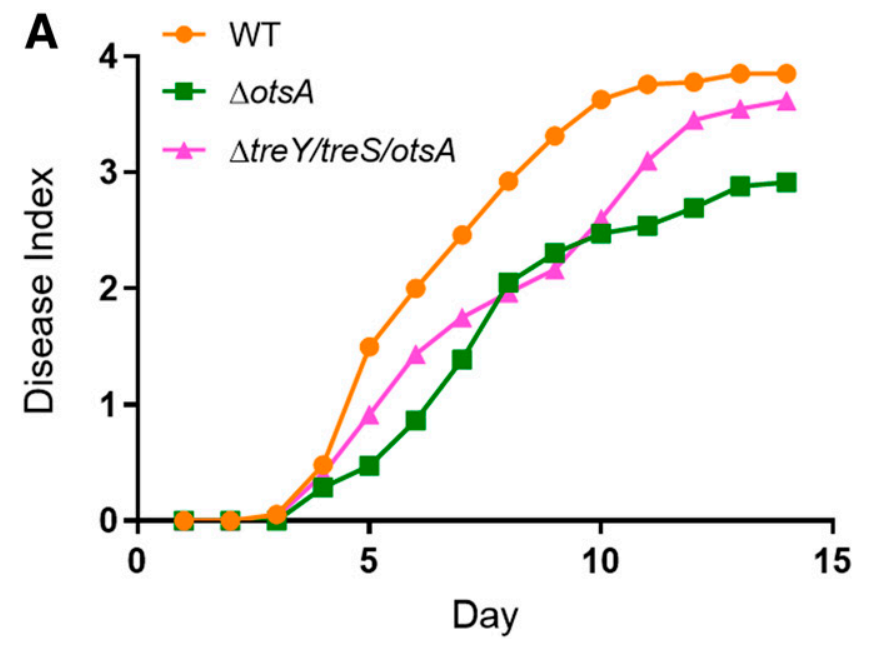

C

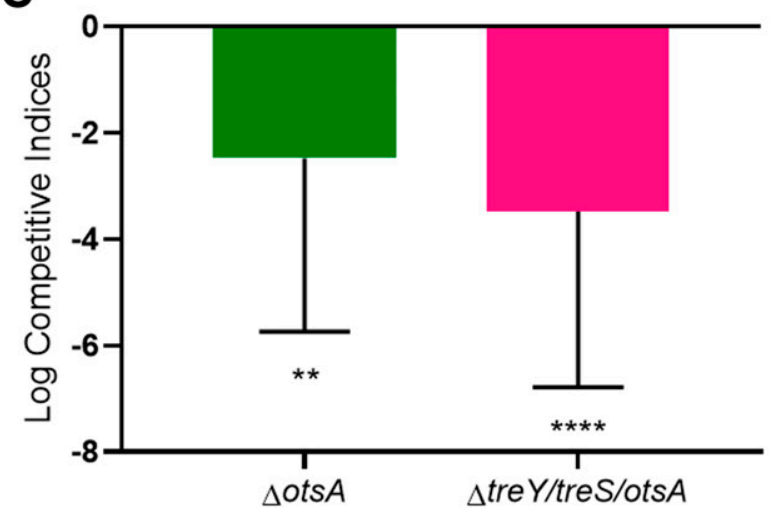

B

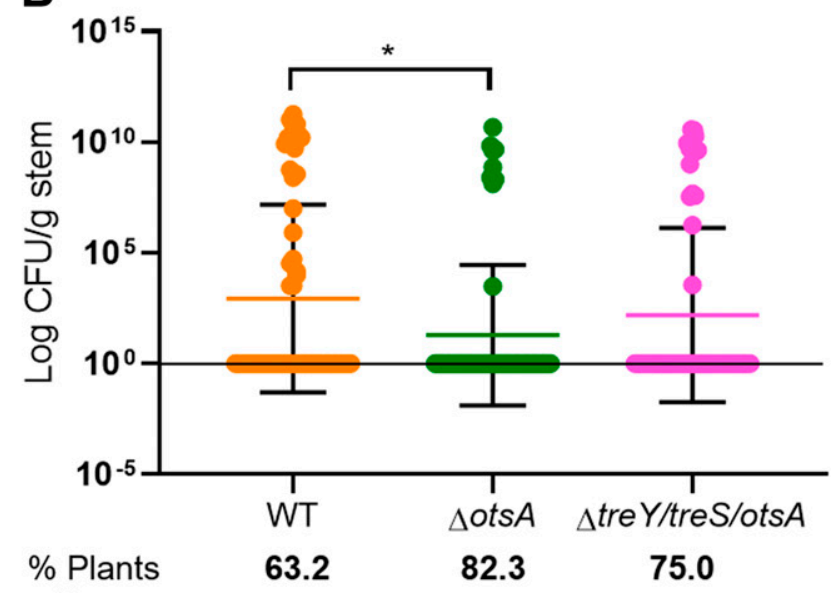

with no

detectable bacteria

Fig. 4. Ralstonia solanacearum requires trehalose synthesis for full virulence and competitive fitness in planta. A, Virulence of wild-type, $\Delta$ otsA, and $\Delta$ treYltreS/otsA R. solanacearum strains following soil-soak inoculation of unwounded tomato plants. Each symbol represents the mean disease index of four biological replicate experiments with 15 plants per treatment per experiment (total $n=60$ plants per treatment). Virulence of wild type was greater than that of $\Delta o t s A$ and $\Delta$ treY/treS/otsA (two-way repeated measures analysis of variance, $P<0.001$ and $P<0.01$, respectively). B, Population sizes of $R$. solanacearum strains in tomato stems $120 \mathrm{~h}$ after soil-soak inoculation, as determined by serial dilution plating of ground midstems. The $\Delta$ ots $A$ mutant did not colonize stems as well as wild-type $R$. solanacearum (Kruskal-Wallis test, $P=0.02$ ); colonization of the $\Delta$ treY/treS/otsA mutant was not significantly different from wild type (Kruskal-Wallis test, $P=0.46$ ). The horizontal bar represents geometric mean population size, and each circle represents the bacterial population size in a single plant (the many uncolonized plants at the zero line are shown as overlapping points). Data are from three independent experiments, each containing 15 plants (total $n=45$ plants per treatment). C, Strain competitive fitness was quantified by measuring population sizes of wild-type and mutant strains in tomato midstems $120 \mathrm{~h}$ after soil-soak inoculation with a 1:1 mixture of wild-type and mutant strains. A score of 0 indicates strains colonized plants equally. Both $\Delta o t s A$ and $\Delta$ treY/treS/ots $A$ had reduced competitive fitness relative to wild type (one-sample $t$ test compared with a hypothetical mean of $0, P=0.0044$ and $P<$ 0.0001 , respectively). Competitive indices (shown here as $\log$ competitive indices) were calculated based on 16 wild type $+\Delta o t s A$-inoculated plants and 36 wild type $+\Delta$ treY/treS/otsA-inoculated plants in three and four independent experiments, respectively. 
To better understand how these mutants failed, we also measured bacterial colonization levels in the tomato midstem following root inoculation. Although the stochastic nature of the root infection process causes variation in initial infection time, mean population sizes of the otsA single mutant were significantly lower than those of wild type 5 days after inoculation. The triple mutant also reached lower mean population sizes, and, although these were not significantly different from those of wild type, this trend may be biologically relevant. Additionally, apart from mean population sizes in the midstem, the single and triple mutants did not colonize as many plants as wild type.

Although trehalose biosynthetic metabolic mutants could achieve near-wild type colonization levels and frequencies when they are inoculated alone, both trehalose mutants were dramatically out-competed when they were coinoculated with wild type. This demonstrates that trehalose biosynthesis gives $R$. solanacearum cells a substantial competitive advantage. Because soil-soak inoculations measure cumulative success, we cannot determine if this competitive advantage accrues during infection, in the harsh xylem habitat, or both. Trehalose could increase ability to tolerate osmotic stress or to overcome other unknown stresses during infection and in planta. For example, in the plant, $R$. solanacearum might encounter low water availability in xylem vessels blocked by air embolisms (Yadeta and Thomma 2013). $R$. solanacearum might also use trehalose to survive locally fluctuating solute potentials when sugars are unloaded into embolized xylem vessels from adjacent phloem or xylem parenchyma to stimulate water refilling (Knipfer et al. 2016; Nardini et al. 2011).

\section{The ots $A B$ pathway is the dominant \\ trehalose synthesis pathway in $R$. solanacearum.}

Although $R$. solanacearum genomes encode three likely pathways for trehalose synthesis, single mutants lacking otsA behaved indistinguishably from the triple mutant strain in most experiments. The treS and tre $Y / Z$ genes are expressed during bacterial growth in tomato, but they could not compensate for the absence of ots $A$, suggesting that OtsA/B is the primary pathway for trehalose synthesis in $R$. solanacearum. This conclusion was further supported by the identically low intracellular levels of trehalose in the single and triple trehalose mutants. Although the TreS and TreY/Z pathways did not contribute to any of the phenotypes we measured, they both link maltose and glycogen metabolism, which may increase $R$. solanacearum fitness under other conditions. In fact, the glycogen-branching enzyme $\operatorname{glg} X$ (Rsp0238) in the same genomic region was recently shown to be under balancing selection in the species complex, indicating this genomic area might be important for more general metabolic diversity (Castillo and Agathos 2019).

\section{The trehalose in xylem sap during infection is likely plant derived.}

LC-MS/MS analysis did not detect trehalose in spent culture media from any $R$. solanacearum strains. Together with the observations that periplasmic tre $A$ is aggressively expressed in culture and in plants and that the in-planta defects of trehalose biosynthetic mutants could not be complemented in trans by coinoculation with wild-type $R$. solanacearum, this result suggests that $R$. solanacearum synthesizes trehalose for intracellular purposes. Thus, the trehalose in xylem sap during infection is likely produced by the plant. $R$. solanacearum differs in this respect from $P$. aeruginosa, which must export significant amounts of trehalose, because the in-planta growth defect of a TreY/TreZ/TreS mutant strain was rescued by coinoculation with wild-type bacteria (Djonović et al. 2013).
If $R$. solanacearum does not export trehalose, why do trehalose levels in tomato xylem sap increase during bacterial wilt disease? Xylem-dwelling wilt pathogens like $R$. solanacearum cause plant water stress, so plants may produce trehalose to overcome this (Daugherty et al. 2010; McElrone et al. 2003). Drought tolerance increases in transgenic plants that overproduce trehalose by overexpressing bacterial or plant T6P synthase (TPS) genes or when plant treA activity is inhibited with validamycin (Cortina and Culiáñez-Macià 2005; Garg et al. 2002; Lyu et al. 2012; Romero et al. 1997). Higher levels of circulating trehalose and T6P in plants could contribute to bacterial wilt resistance by priming plants to better tolerate the drought-like conditions of wilt disease. In fact, treating plants with validamycin, which inhibits trehalase, has been shown to decrease bacterial wilt incidence (Ishikawa et al. 1996). Ongoing studies will determine if increased trehalose in xylem sap or other tissues contributes to water conservation or to bacterial wilt tolerance.

Fruits and leaves of water-deprived tomato plants contain increased sugar, which could benefit $R$. solanacearum by serving as a nutrient (Ripoll et al. 2014; Ximénez-Embún et al. 2016). Our observation that xylem sap from infected plants supports better bacterial growth than sap from healthy plants suggests that $R$. solanacearum somehow increases nutrient concentrations in sap (Lowe-Power et al. 2018a). The existence of the type III-secreted effector TPS (RipTPS) also hints at an active pathogen role in manipulating plant trehalose metabolism (Poueymiro et al. 2014). However, although strain GMI1000 can grow on trehalose as a sole carbon source, this sugar is not a significant carbon source for $R$. solanacearum during tomato colonization and pathogenesis, and trehalose is present in xylem sap at much lower concentrations than the more palatable sucrose (Hamilton et al. 2019).

Our finding that $R$. solanacearum trehalose biosynthesis contributes to successful bacterial wilt disease adds to the evidence that this disaccharide plays important roles in plantbacterial interactions. Ongoing experiments are exploring the plant side of the interaction to see if tomato trehalose metabolism helps defend plants from bacterial wilt disease or is manipulated to the advantage of the pathogen.

\section{MATERIALS AND METHODS}

\section{Comparative genomics.}

Candidate trehalose metabolism pathways were identified in all finished, permanent draft, and draft genomes of $R$. solanacearum strains available on the Joint Genome Institute Integrated Microbial Genomes (JGI/IMG) database on June 30, 2019, using BLASTN with standard settings (E value 1e-5). BLAST nucleotide template search sequences were derived from the well-characterized trehalose metabolic pathways in E. coli and P. aeruginosa (Djonović et al. 2013; Freeman et al. 2010; Piazza et al. 2015). Some $R$. solanacearum genes were already annotated as related to trehalose synthesis (Poueymiro et al. 2014).

\section{R. solanacearum culture conditions.}

E. coli strains were grown on Luria-Bertani medium at $37^{\circ} \mathrm{C}$. $R$. solanacearum strains were cultured from water stocks or $-80^{\circ} \mathrm{C}$ glycerol stocks on TZC plates containing casamino acids, peptone, glucose, and tetrazolium chloride, supplemented with antibiotics when needed $(20 \mathrm{mg}$ per liter of spectinomycin, $15 \mathrm{mg}$ per liter per liter of gentamicin, and $25 \mathrm{mg}$ per liter of kanamycin), and incubated at $28^{\circ} \mathrm{C}$ for $48 \mathrm{~h}$ (Hendrick and Sequeira 1984). For isolations from soil, a semiselective version of TZC media was supplemented with polymyxin B sulfate at $100 \mathrm{mg} / \mathrm{ml}$, bacitracin at $25 \mathrm{mg} / \mathrm{ml}$, 
penicillin-G at $0.5 \mathrm{mg} / \mathrm{ml}$, chloramphenicol at $5 \mathrm{mg} / \mathrm{ml}$, and cycloheximide at $100 \mathrm{mg} / \mathrm{ml}$. Overnight cultures of $R$. solanacearum were grown at $28^{\circ} \mathrm{C}$ in CPG (casamino peptone agar) or BMM broth supplemented with $0.2 \%$ glucose (wt/vol) $(\mathrm{pH} 7.0)$ in a shaking incubator (Boucher et al. 1985).

\section{$\boldsymbol{R}$. solanacearum molecular cloning.}

Genomic and plasmid DNA isolation, PCR, and transformation were carried out as described (Ausubel et al. 2003; Kang et al. 1994). The $\Delta$ tre $Y$ and $\Delta$ treS unmarked, in-frame, complete gene-deletion strains were constructed by amplifying regions up- and downstream of the target area, cloning the amplicons into the pUFR80 vector, using Gibson Assembly (New England Biolabs), and selecting candidate mutants as described (Castañeda et al. 2005). The $\Delta$ treA mutant was created by amplifying the regions upstream and downstream of the tre $A$ gene and inserting the streptomycin/spectinomycin resistance cassette from pCR8 (Thermo Fisher). The $\triangle$ otsA mutant was constructed by amplifying regions up- and downstream of the target coding sequence and inserting a gentamicin resistance cassette. For both the $\Delta t r e A$ and $\Delta o t s A$ mutants, the resulting three PCR fragments were combined and were cloned into E. coli. Mutagenesis constructs were transformed into $R$. solanacearum GMI1000 by electroporation, and homologous recombinants were selected on antibiotic-containing medium. Downstream polar effects are unlikely for both the $\Delta t r e A$ and $\triangle o t s A$ mutants, because tre $A$ is monocistronic and the gene downstream of the otsBA operon is distant and not in frame. Polymutants were created via natural transformation (Kang et al. 1994). All mutants were confirmed with PCR and sequencing of the target region.

\section{Cell lysate extraction and chromatographic quantification of intracellular trehalose.}

$R$. solanacearum strains were grown overnight in $100 \mathrm{ml}$ of $\mathrm{BMM}+0.2 \%$ glucose at $28^{\circ} \mathrm{C}$. About $10^{10} \mathrm{CFU}$ were pelleted and were resuspended three times at $4^{\circ} \mathrm{C}$ in cold high-pressure liquid chromatography (HPLC)-grade water; samples were kept on ice during manipulation. Supernatant was removed, and pellets were weighed and were flash frozen in liquid $\mathrm{N}_{2}$. Aliquots $(200 \mu \mathrm{l})$ of spent media for each strain were also flash-frozen. Frozen cell pellets were resuspended in $1 \mathrm{ml}$ of HPLC-grade water with $20 \mathrm{mg}$ of lysozyme per milliliter (Sigma-Aldrich), on ice, and were incubated for $45 \mathrm{~min}$. Cell suspensions were then sonicated with a needle sonicator at $40 \%$ amplification for 1030 -s pulse cycles. Samples were kept on ice between sonication cycles. After sonication, cell suspensions were stained with $0.4 \%$ trypan blue and were assessed microscopically to ensure no viable bacterial cells remained. Cell debris was pelleted at $4^{\circ} \mathrm{C}$ for $5 \mathrm{~min}$ at $3,500 \times g$. Aliquots $(200 \mu \mathrm{l})$ of cell lysate supernatant were flash frozen. Spent media and cell lysate samples were stored at $-80^{\circ} \mathrm{C}$ until analysis.

Trehalose in cell lysates was quantified by LC-MS/MS using a Waters Acquity ultra-performance liquid chromatography (UPLC) system coupled to an AB Sciex Q-Trap 5500 triple quadrupole mass spectrometer, using modified methods (Hayner et al. 2017). The internal standard (ISTD), ${ }^{13} \mathrm{C}_{12}$-trehalose, was purchased from Toronto Research Chemicals and D$(+)$-trehalose dihydrate $(>99 \%)$ and solvents were purchased from Fisher Scientific. A standard curve for trehalose with seven points $(1,3,6,10,30,60$, and $300 \mathrm{ng} / \mathrm{ml})$ was prepared in water. Samples $(200 \mu \mathrm{l})$ of cell lysate, standards, and qualitycontrol samples were processed on an Ostro 96-well plate, using a positive-pressure manifold after addition of four volumes acetonitrile containing $10 \mathrm{ng}$ of ISTD per milliliter. Following processing, samples were dried under nitrogen for $1 \mathrm{~h}$ and were resuspended in $100 \mu \mathrm{l}$ of mobile phase A
(80\% acetonitrile: $20 \% \mathrm{H}_{2} \mathrm{O}$ [vol/vol] with $1 \mathrm{mM}$ ammonium bicarbonate, $\mathrm{pH}$ 9.4). Samples (5- $\mu 1$ injections) were separated on a Waters Acquity UPLC BEH amide column $(2.1 \times 150 \mathrm{~mm}$, $1.7 \mu \mathrm{m}$ particle size) using an increasing gradient of solvent $\mathrm{B}$ (70\% acetonitrile: $30 \% \mathrm{H}_{2} \mathrm{O}$ [vol/vol] with $1 \mathrm{mM}$ ammonium bicarbonate, $\mathrm{pH}$ 9.6; solvent $\mathrm{A}$ described above). Saccharides were separated using an 11-min gradient. The gradient started at $5 \% \mathrm{~B}$ and increased to $10 \% \mathrm{~B}$ in $7 \mathrm{~min}$, then to $50 \% \mathrm{~B}$ in $0.5 \mathrm{~min}$ with a 1.5 -min hold, then back to $5 \% \mathrm{~B}$ in $0.5 \mathrm{~min}$ with a re-equilibration hold for $1.5 \mathrm{~min}$. The column temperature was $28^{\circ} \mathrm{C}$ and the flow was $0.3 \mathrm{ml} / \mathrm{min}$. Samples were analyzed with triplicate injections, including a blank between each replicate. Transitions for trehalose were 341 to 89,119 , and 179 . Transitions for ${ }^{13} \mathrm{C}_{12}$-trehalose ISTD were 353 to 92,123 , and 185. Quantitation was based on 341 to 119 transition with a 353 to 185 transition used for the ISTD. Data analysis was performed using MultiQuant version 3.0.1 software (AB Sciex), fitting the data to a quadratic model with $1 / x^{2}$ weighting. A typical lower level of quantification (LOQ) was $0.5 \mathrm{ng} / \mathrm{ml}$ with a typical upper LOQ of $300 \mathrm{ng} / \mathrm{ml}$.

\section{Chronic temperature stress.}

Overnight cultures of $R$. solanacearum were centrifuged, were rinsed twice, and were resuspended at $1 \times 10^{7} \mathrm{CFU}$ per milliliter in 96-well plates in BMM $+0.2 \%$ glucose. Plates were incubated in a BioTek plate reader with shaking at 28 (optimal growth temperature), 37 , and $40^{\circ} \mathrm{C}$ for $48 \mathrm{~h}$. Growth was measured spectrophotometrically as optical density at $600 \mathrm{~nm}$ $\left(\mathrm{OD}_{600}\right)$ every $15 \mathrm{~min}$. Each experiment included eight technical replicates per treatment and the experiment was replicated three times. To measure growth at the suboptimal temperature of $20^{\circ} \mathrm{C}$, overnight cultures of GMI1000 were spun down and were resuspended at $1 \times 10^{5} \mathrm{CFU}$ per milliliter in $50 \mathrm{ml}$ of $\mathrm{BMM}+0.2 \%$ glucose in $150-\mathrm{ml}$ flasks in a shaking incubator held at $20^{\circ} \mathrm{C}$. Flasks were sampled daily until bacteria reached $1 \times 10^{9} \mathrm{CFU}$ per milliliter. Cells were enumerated with serial dilution plating.

\section{Heat shock.}

Overnight cultures of $R$. solanacearum were centrifuged, were rinsed twice, and were resuspended in sterile water to $1 \times$ $10^{8} \mathrm{CFU}$ per milliliter. A total of $100 \mu \mathrm{l}$ of cell suspension was exposed to 45,46 , or $47^{\circ} \mathrm{C}$ for $10 \mathrm{~min}$ in an Arktik thermal cycler (Thermo Scientific) and then was returned to $22^{\circ} \mathrm{C}$. Surviving cells were enumerated with serial dilution plating. The percent $\log _{10}$ recovery was calculated as surviving CFU based on the initial cell concentration. Each assay contained six technical replicates per strain and the experiment was replicated three times.

\section{Oxidative stress assays with paraquat.}

Response of the $\Delta$ otsA and $\Delta$ treY/treS/otsA mutant strains to oxidative stress was assayed by measuring bacterial growth over time in $\mathrm{BMM}+0.2 \%$ glucose supplemented with 0 or $10 \mu \mathrm{M}$ concentrations of the herbicide paraquat (Flores-Cruz and Allen 2011). Plates were incubated in a BioTek plate reader with shaking at $28^{\circ} \mathrm{C}$ and growth was measured spectrophotometrically as $\mathrm{OD}_{600}$ every $15 \mathrm{~min}$ for $48 \mathrm{~h}$. Each assay contained seven technical replicates per strain and the experiment was replicated four times.

\section{Desiccation survival assays.}

Overnight cultures of $R$. solanacearum strains were pelleted, were rinsed three times in sterile water, were resuspended in water, and were adjusted to $1 \times 10^{9} \mathrm{CFU}$ per milliliter. A total of $100 \mu \mathrm{l}$ of cell suspension was pipetted onto $25-\mathrm{mm}$ nitrocellulose membranes (Millipore) in a biosafety cabinet under 
airflow and was left to dry for $45 \mathrm{~min}$. Dried filters were placed in microcentrifuge tubes containing $900 \mu \mathrm{l}$ of sterile water, were vortexed for $1 \mathrm{~min}$, and surviving cells were enumerated, using serial dilution plating of the water. The percent $\log _{10}$ recovery was calculated as surviving CFU based on the initial cell concentration. Each assay contained six technical replicates per strain and the experiment was replicated four times.

\section{Biofilm formation.}

Biofilm formation on PVC plates was assessed using crystal violet stain (Yao and Allen 2007). Briefly, R. solanacearum cells resuspended at $\mathrm{OD}_{600}=0.01$ were incubated without shaking overnight in 96-well PVC plates. Medium was removed and biofilm clinging to the walls of the wells was stained with crystal violet, dissolved in ethanol, and absorbance at $560 \mathrm{~nm}$ was measured using a BioTek plate reader.

\section{Osmotic stress.}

Overnight cultures of $R$. solanacearum were centrifuged, were rinsed twice, and were resuspended at $1 \times 10^{7} \mathrm{CFU}$ per milliliter in 96-well plates in either CPG broth supplemented with $0.15 \mathrm{M} \mathrm{NaCl}$ (50\% decrease in growth fitness) or CPG containing $15 \%$ PEG-4000 dissolved in water. CPG diluted with water to equal the amount of volume of $\mathrm{NaCl}$ or PEG solution was used as a control. Plates were incubated in a BioTek plate reader with shaking at $28^{\circ} \mathrm{C}$. Growth was measured spectrophotometrically as $\mathrm{OD}_{600}$ every $15 \mathrm{~min}$ for $48 \mathrm{~h}$. Each experiment included eight technical replicates per treatment and the experiment was replicated three times.

\section{Plant assays.}

$R$. solanacearum virulence on tomato plants was measured as described (Khokhani et al. 2018; Tans-Kerstenet al. 1998). Briefly, 15-day-old unwounded tomato plants (wilt-susceptible $\mathrm{cv}$. Bonny Best) were inoculated by pouring into each pot $50 \mathrm{ml}$ of a $5 \times 10^{7} \mathrm{CFU}$ per milliliter $R$. solanacearum cell suspension in water. Plants were rated daily on a 0 to 4 disease index scale in which $0=$ no symptoms, $1=1$ to $25 \%$ of leaf area wilted, $2=$ 26 to $50 \%, 3=51$ to $75 \%$, and $4=76$ to $100 \%$ of leaf area wilted or dead. Each virulence assay contained 15 plants per treatment and the experiment was replicated four times. Colonization ability of $R$. solanacearum strains was assessed by dilution plating a ground tomato midstem section 5 days after soil-soak inoculation as described above (Dalsing and Allen 2014). Each colonization assay contained 15 plants per treatment, and the experiment was replicated four times. Competitive fitness of the $\Delta$ ots $A$ and $\Delta$ treY/treS/otsA strains relative to their wild-type parent was assessed as described (Yao and Allen 2006). Briefly, tomato plants were soil-soak inoculated with $50 \mathrm{ml}$ of a 1:1 suspension of wild-type $R$. solanacearum $\left(\operatorname{Kan}^{\mathrm{R}}\right)$ and either the $\Delta$ ots $A$ or the $\Delta$ treY/treS/otsA mutant (both $\mathrm{Gm}^{\mathrm{R}}$ ) at $5 \times 10^{7} \mathrm{CFU}$ of each competing strain per milliliter. The population size of each competing strain was determined 5 days after inoculation by serial dilution plating of a ground midstem section on appropriate selective media. $\log _{10}$ normalized competitive fitness index values were calculated as: (mutant final population/wild-type final population) / (mutant initial population/wild-type initial population). A score of 0 indicates strains were equally successful within the plant. Competitive fitness assays contained 15 plants per strain and were replicated three or four times. Data from "escaped" plants that were not colonized by either strain were not included in this analysis.

\section{Long-term survival in soil.}

Three-week-old Bonny Best tomato plants grown in Magenta boxes were inoculated by placing a droplet containing 2,000 $R$. solanacearum cells on the surface of a freshly cut leaf petiole to ensure that any pathogen cells in the soil had passed through the plant, because passage through plants primes $R$. solanacearum for soil survival (Scherf et al. 2010). When plants reached disease index 4 , they were uprooted from their box. Each box was capped to prevent evaporation, and boxes were stored at $28^{\circ} \mathrm{C}$. Each week a 0.5 -g soil sample from each box was suspended in water and serially dilution-plated on semiselective CPG media, to enumerate cells. Data shown represent five technical replicates per strain from one experiment.

\section{Long-term survival in potato tubers.}

$R$. solanacearum survival in potato tubers at the common tuber storage temperature of $4^{\circ} \mathrm{C}$ was measured as described (Milling et al. 2009). Briefly, 15- to 17-mm diameter mini tubers of wiltsusceptible cv. Russet Norkotah (Sklarczyk Seed Farm) were inoculated at the stolon end with $2 \mu$ l containing $2 \times 10^{7} \mathrm{CFU}$ of antibiotic-resistant $R$. solanacearum. Tubers were destructively sampled, at the site of inoculation, weekly and cells were enumerated by dilution-plating ground tissue on semiselective CPG plates. Colonies were tested with AgDia $R$. solanacearum immunostrips (AgDia) to confirm $R$. solanacearum growth. Data shown are mean population sizes from four tubers per strain per week and the experiment was repeated twice.

\section{Long-term survival in cold water.}

$R$. solanacearum survival in water at $4{ }^{\circ} \mathrm{C}$ was assessed as described (Milling et al. 2009). Briefly, overnight cultures of $R$. solanacearum cells were rinsed three times and were resuspended at a concentration of $1 \times 10^{8} \mathrm{CFU} / \mathrm{ml}$ in $10 \mathrm{ml}$ of sterile MilliQ water. Cells were then starved at room temperature for 2 days, were sampled to determine initial CFU per milliliter, and were moved to $4^{\circ} \mathrm{C}$. Survival was determined by serial dilution plating. Replicates were sampled weekly until cells could no longer be recovered. Data represent two technical replicates per strain and the experiment was repeated four times.

\section{Statistical analyses.}

Statistical analyses were carried out using GraphPad Prism 8 package.

\section{ACKNOWLEDGMENTS}

We thank C. Heileman for his contribution to long-term survival assays in potato tubers and soil, T. Lowe-Power for treS construct design, and C. Hamilton for valuable discussion.

\section{AUTHOR-RECOMMENDED INTERNET RESOURCES}

BLASTN database: https://img.jgi.doe.gov/cgi-bin/m/main.cgi?section= FindGenesBlast\&page $=$ geneSearchBlast

KEGG Modules database: https://www.genome.jp/kegg/module.html

\section{LITERATURE CITED}

Álvarez, B., Bosca, E. G., and López, M. M. 2010. On the life of Ralstonia solanacearum, a destructive bacterial plant pathogen. Pages 267-279 in: Technology and Education Topics in Applied Mcrobiology and Microbial Biotechnology, Vol. 1. A. Mendez-Vilas, ed. Formatex, Badajoz, Spain.

Ausubel, F. M., Brent, R., Kingston, R. E., Moore, D. D., Seidman, J. G., Smith, J. A., and Struhl, K. 2003. Current Protocols in Molecular Biology. John Wiley \& Sons, Inc., New York.

Avonce, N., Leyman, B., Mascorro-Gallardo, J. O., Van Dijck, P., Thevelein, J. M., and Iturriaga, G. 2004. The Arabidopsis trehalose-6P synthase AtTPS1 gene is a regulator of glucose, abscisic acid, and stress signaling. Plant Physiol. 136:3649-3659.

Avonce, N., Mendoza-Vargas, A., Morett, E., and Iturriaga, G. 2006. Insights on the evolution of trehalose biosynthesis. BMC Evol. Biol. 6:109. 
Bae, H., Herman, E., Bailey, B., Bae, H.-J., and Sicher, R. 2005. Exogenous trehalose alters Arabidopsis transcripts involved in cell wall modification, abiotic stress, nitrogen metabolism, and plant defense. Physiol. Plant. 125:114-126.

Benaroudj, N., Lee, D. H., and Goldberg, A. L. 2001. Trehalose accumulation during cellular stress protects cells and cellular proteins from damage by oxygen radicals. J. Biol. Chem. 276:24261-24267.

Bialczyk, J., Lechowski, Z., and Dziga, D. 2004. 'Composition of the xylem sap of tomato seedlings cultivated on media with $\mathrm{HCO}_{3}{ }^{-}$and nitrogen source as $\mathrm{NO}_{3}{ }^{-}$or $\mathrm{NH}_{4}{ }^{+}$. Plant Soil 263:265-272.

Boucher, C. A., Barberis, P. A., Trigalet, A. P. H., and Demery, D. A. 1985. Transposon mutagenesis of Pseudomonas solanacearum: Isolation of Tn5- induced avirulent mutants. J. Gen. Microbiol. 131:2449-2457.

Castañeda, A., Reddy, J. D., El-Yacoubi, B., and Gabriel, D. W. 2005. Mutagenesis of all eight avr genes in Xanthomonas campestris pv. campestris had no detected effect on pathogenicity, but one avr gene affected race specificity. Mol. Plant-Microbe Interact. 18:1306-1317.

Castillo, J. A., and Agathos, S. N. 2019. A genome-wide scan for genes under balancing selection in the plant pathogen Ralstonia solanacearum. BMC Evol. Biol. 19:123.

Cortina, C., and Culiáñez-Macià, F. A. 2005. Tomato abiotic stress enhanced tolerance by trehalose biosynthesis. Plant Sci. 169:75-82.

Csonka, L. N. 1989. Physiological and genetic responses of bacteria to osmotic stress. Microbiol. Rev. 53:121-147.

Dalsing, B. L., and Allen, C. 2014. Nitrate assimilation contributes to Ralstonia solanacearum root attachment, stem colonization, and virulence. J. Bacteriol. 196:949-960.

Daugherty, M. P., Lopes, J. R. S., and Almeida, R. P. P. 2010. Strain-specific alfalfa water stress induced by Xylella fastidiosa. Eur. J. Plant Pathol 127:333-340.

Denny, T. P. 2006. Pages 573-644 in: Plant-Associated Bacteria. S. S. Gnanamanickam, ed. Springer, Dordrecht, The Netherlands.

Djonović, S., Urbach, J. M., Drenkard, E., Bush, J., Feinbaum, R., Ausubel, J. L., Traficante, D., Risech, M., Kocks, C., Fischbach, M. A., Priebe, G. P., and Ausubel, F. M. 2013. Trehalose biosynthesis promotes Pseudomonas aeruginosa pathogenicity in plants. PLoS Pathog. 9: e1003217.

Elphinstone, J. G. 2005. The current bacterial wilt situation: A global overview. In: Bacterial Wilt Disease and the Ralstonia solanacearum Species Complex. C. Allen, P. Prior, and A. C. Hayward. eds. American Phytopathological Society, St. Paul, MN, U.S.A.

Flores-Cruz, Z., and Allen, C. 2009. Ralstonia solanacearum encounters an oxidative environment during tomato infection. Mol. Plant-Microbe Interact. 22:773-782.

Flores-Cruz, Z., and Allen, C. 2011. Necessity of OxyR for the hydrogen peroxide stress response and full virulence in Ralstonia solanacearum. Appl. Environ. Microbiol. 77:6426-6432.

Freeman, B. C., Chen, C., and Beattie, G. A. 2010. Identification of the trehalose biosynthetic loci of Pseudomonas syringae and their contribution to fitness in the phyllosphere. Environ. Microbiol. 12: 1486-1497.

Garg, A. K., Kim, J.-K., Owens, T. G., Ranwala, A. P., Choi, Y. D., Kochian, L. V., and Wu, R. J. 2002. Trehalose accumulation in rice plants confers high tolerance levels to different abiotic stresses. Proc. Natl. Acad. Sci. U.S.A. 99:15898-1590.

Graham, J., and Lloyd, A. B. 1979. Survival of potato strain (race 3) of Pseudomonas solanacearum in the deeper soil layers. Aust. J. Agric. Res. 30:489-496.

Hamilton, C. D., Steidl, O., MacIntyre, A. M., and Allen, C. 2019. Ralstonia solanacearum depends on catabolism of myo-inositol, sucrose, and trehalose for virulence in an infection stage-dependent manner. bioRxiv:700351.

Hayner, G. A., Khetan, S., and Paulick, M. G. 2017. Quantification of the disaccharide trehalose from biological samples: A comparison of analytical methods. ACS Omega 2:5813-5823.

Hayward, A. C. 1991. Biology and epidemiology of bacterial wilt caused by Pseudomonas solanacearum. Annu. Rev. Phytopathol. 29:65-87.

Hendrick, C. A., and Sequeira, L. 1984. Lipopolysaccharide-defective mutants of the wilt pathogen Pseudomonas solanacearum. Appl. Environ. Microbiol. 48:94-101.

Huang, Q., and Allen, C. 1997. An exo-poly- $\alpha$-D-galacturonosidase, PehB, is required for wild-type virulence of Ralstonia solanacearum. J. Bacteriol. 179:7369-7378.

Huang, Q., and Allen, C. 2000. Polygalacturonases are required for rapid colonization and full virulence of Ralstonia solanacearum on tomato plants. Physiol. Mol. Plant Pathol. 57:77-83.

Iordachescu, M., and Imai, R. 2008. Trehalose biosynthesis in response to abiotic stresses. J. Integr. Plant Biol. 50:1223-1229.
Ishikawa, R., Fujimori, K., and Matsuura, K. 1996. Antibacterial activity of validamycin A against Pseudomonas solanacearum and its efficacy against tomato bacterial wilt. Ann. Phytopathol. Soc. Jpn. 62:478-482.

Iturriaga, G., Suárez, R., and Nova-Franco, B. 2009. Trehalose metabolism: From osmoprotection to signaling. Int. J. Mol. Sci. 10:3793-3810.

Jacobs, J. M., Babujee, L., Meng, F., Milling, A., and Allen, C. 2012. The in planta transcriptome of Ralstonia solanacearum: Conserved physiological and virulence strategies during bacterial wilt of tomato. MBio 3: e00114-12.

Kandror, O., DeLeon, A., and Goldberg, A. L. 2002. Trehalose synthesis is induced upon exposure of Escherichia coli to cold and is essential for viability at low temperatures. Proc. Natl. Acad. Sci. U.S.A. 99:9727-9732

Kang, Y., Huang, J., Mao, G., He, L.-Y., and Schell, M. A. 1994. Dramatically reduced virulence of mutants of Pseudomonas solanacearum defective in export of extracellular proteins across the outer membrane. Mol. Plant-Microbe Interact. 7:370-377.

Khokhani, D., Lowe-Power, T. M., Tran, T. M., and Allen, C. 2017. A single regulator mediates strategic switching between attachment/spread and growth/virulence in the plant pathogen Ralstonia solanacearum. MBio 8:e00895-17.

Khokhani, D., Tuan, T., Lowe-Power, T., and Allen, C. 2018. Plant assays for quantifying Ralstonia solanacearum virulence. Bio Protoc. 8.

Knipfer, T., Cuneo, I. F., Brodersen, C. R., and McElrone, A. J. 2016. In situ visualization of the dynamics in xylem embolism formation and removal in the absence of root pressure: A study on excised grapevine stems. Plant Physiol. 171:1024-1036.

Kolbe, A., Tiessen, A., Schluepmann, H., Paul, M., Ulrich, S., and Geigenberger, P. 2005. Trehalose 6-phosphate regulates starch synthesis via posttranslational redox activation of ADP-glucose pyrophosphorylase. Proc. Natl. Acad. Sci. U.S.A. 102:11118-11123.

Lee, J. H., Lee, K. H., Kim, C. G., Lee, S. Y., Kim, G. J., Park, Y. H., and Chung, S. O. 2005. Cloning and expression of a trehalose synthase from Pseudomonas stutzeri CJ38 in Escherichia coli for the production of trehalose. Appl. Microbiol. Biotechnol. 68:213-219.

Lowe-Power, T. M., Hendrich, C. G., von Roepenack-Lahaye, E., Li, B., Wu, D., Mitra, R., Dalsing, B. L., Ricca, P., Naidoo, J., Cook, D., Jancewicz, A., Masson, P., Thomma, B., Lahaye, T., Michael, A. J., and Allen, C. 2018a. Metabolomics of tomato xylem sap during bacterial wilt reveals Ralstonia solanacearum produces abundant putrescine, a metabolite that accelerates wilt disease. Environ. Microbiol. 20:1330-1349.

Lowe-Power, T. M., Jacobs, J. M., Ailloud, F., Fochs, B., Prior, P., and Allen, C. 2016. Degradation of the plant defense signal salicylic acid protects Ralstonia solanacearum from toxicity and enhances virulence on tobacco. MBio 7:e00656-16.

Lowe-Power, T. M., Khokhani, D., and Allen, C. 2018b. How Ralstonia solanacearum exploits and thrives in the flowing plant xylem environment. Trends Microbiol. 26:929-942.

Lunn, J. E., Delorge, I., Figueroa, C. M., Van Dijck, P., and Stitt, M. 2014. Trehalose metabolism in plants. Plant J. 79:544-567.

Lunn, J. E., Feil, R., Hendriks, J. H., Gibon, Y., Morcuende, R., Osuna, D., Scheible, W. R., Carillo, P., Hajirezaei, M. R., and Stitt, M. 2006. Sugarinduced increases in trehalose 6-phosphate are correlated with redox activation of ADPglucose pyrophosphorylase and higher rates of starch synthesis in Arabidopsis thaliana. Biochem. J. 397:139-148.

Lyu, J. I., Min, S. R., Lee, J. H., Lim, Y. H., Kim, J.-K., Bae, C.-H., and Liu, J. R. 2012. Overexpression of a trehalose-6-phosphate synthase/phosphatase fusion gene enhances tolerance and photosynthesis during drought and salt stress without growth aberrations in tomato. Plant Cell Tissue Organ Cult. 112:257-262.

McElrone, A. J., Sherald, J. L., and Forseth, I. N. 2003. Interactive effects of water stress and xylem-limited bacterial infection on the water relations of a host vine. J. Exp. Bot. 54:419-430.

Milling, A., Meng, F., Denny, T. P., and Allen, C. 2009. Interactions with hosts at cool temperatures, not cold tolerance, explain the unique epidemiology of Ralstonia solanacearum race 3 biovar 2. Phytopathology 99:1127-1134.

Mori, Y., Inoue, K., Ikeda, K., Nakayashiki, H., Higashimoto, C., Ohnishi, K., Kiba, A., and Hikichi, Y. 2016. The vascular plant-pathogenic bacterium Ralstonia solanacearum produces biofilms required for its virulence on the surfaces of tomato cells adjacent to intercellular spaces. Mol. Plant Pathol. 17:890-902.

Murphy, H. N., Stewart, G. R., Mischenko, V. V., Apt, A. S., Harris, R., McAlister, M. S., Driscoll, P. C., Young, D. B., and Robertson, B. D. 2005. The OtsAB pathway is essential for trehalose biosynthesis in Mycobacterium tuberculosis. J. Biol. Chem. 280:14524-14529.

Nardini, A., Lo Gullo, M. A., and Salleo, S. 2011. Refilling embolized xylem conduits: Is it a matter of phloem unloading? Plant Sci. 180: 604-611. 
Orgambide, G., Montrozier, H., Servin, P., Roussel, J., Trigalet-Demery, D., and Trigalet, A. 1991. High heterogeneity of the exopolysaccharides of Pseudomonas solanacearum strain GMI 1000 and the complete structure of the major polysaccharide. J. Biol. Chem. 266:8312-8321.

Paul, M. J., Primavesi, L. F., Jhurreea, D., and Zhang, Y. 2008. Trehalose metabolism and signaling. Annu. Rev. Plant Biol. 59:417-441.

Perrier, A., Barlet, X., Peyraud, R., Rengel, D., Guidot, A., and Genin, S. 2018. Comparative transcriptomic studies identify specific expression patterns of virulence factors under the control of the master regulator PhcA in the Ralstonia solanacearum species complex. Microb. Pathog. 116:273-278.

Peyraud, R., Cottret, L., Marmiesse, L., Gouzy, J., and Genin, S. 2016. A resource allocation trade-off between virulence and proliferation drives metabolic versatility in the plant pathogen Ralstonia solanacearum. PLoS Pathog. 12:e1005939.

Piazza, A., Zimaro, T., Garavaglia, B. S., Ficarra, F. A., Thomas, L., Marondedze, C., Feil, R., Lunn, J. E., Gehring, C., Ottado, J., and Gottig, N. 2015. The dual nature of trehalose in citrus canker disease: A virulence factor for Xanthomonas citri subsp. citri and a trigger for plant defence responses. J. Exp. Bot. 66:2795-2811.

Poueymiro, M., Cazalé, A. C., François, J. M., Parrou, J. L., Peeters, N., and Genin, S. 2014. A Ralstonia solanacearum type III effector directs the production of the plant signal metabolite trehalose-6-phosphate. MBio 5: e02065-14.

Poueymiro, M., and Genin, S. 2009. Secreted proteins from Ralstonia solanacearum: A hundred tricks to kill a plant. Curr. Opin. Microbiol. 12:44-52.

Purvis, J. E., Yomano, L. P., and Ingram, L. O. 2005. Enhanced trehalose production improves growth of Escherichia coli under osmotic stress. Appl. Environ. Microbiol. 71:3761-3769.

Reina-Bueno, M., Argandoña, M., Nieto, J. J., Hidalgo-García, A., IglesiasGuerra, F., Delgado, M. J., and Vargas, C. 2012. Role of trehalose in heat and desiccation tolerance in the soil bacterium Rhizobium etli. BMC Microbiol. 12:207.

Ripoll, J., Urban, L., Staudt, M., Lopez-Lauri, F., Bidel, L. P., and Bertin, N. 2014. Water shortage and quality of fleshy fruits-Making the most of the unavoidable. J. Exp. Bot. 65:4097-4117.

Romero, C., Bellés, J. M., Vayá, J. L., Serrano, R., and Culiáñez-Macià, F. A. 1997. Expression of the yeast trehalose-6-phosphate synthase gene in transgenic tobacco plants: Pleiotropic phenotypes include drought tolerance. Planta 201:293-297.

Scherf, J. M., Milling, A., and Allen, C. 2010. Moderate temperature fluctuations rapidly reduce the viability of Ralstonia solanacearum race 3 , biovar 2, in infected geranium, tomato, and potato plants. Appl. Environ. Microbiol. 76:7061-7067.

Singh, V., Louis, J., Ayre, B. G., Reese, J. C., Pegadaraju, V., and Shah, J. 2011. TREHALOSE PHOSPHATE SYNTHASE11-dependent trehalose metabolism promotes Arabidopsis thaliana defense against the phloemfeeding insect Myzus persicae. Plant J. 67:94-104.

Singh, V., and Shah, J. 2012. Tomato responds to green peach aphid infestation with the activation of trehalose metabolism and starch accumulation. Plant Signal. Behav. 7:605-607.

Sleator, R. D., and Hill, C. 2002. Bacterial osmoadaptation: The role of osmolytes in bacterial stress and virulence. FEMS Microbiol. Rev. 26: 49-71.

Strøm, A. R., and Kaasen, I. 1993. Trehalose metabolism in Escherichia coli: Stress protection and stress regulation of gene expression. Mol Microbiol. 8:205-210.

Tans-Kersten, J., Guan, Y., and Allen, C. 1998. Ralstonia solanacearum pectin methylesterase is required for growth on methylated pectin but not for bacterial wilt virulence. Appl. Environ. Microbiol. 64:4918-4923.

Tans-Kersten, J., Huang, H., and Allen, C. 2001. Ralstonia solanacearum needs motility for invasive virulence on tomato. J. Bacteriol. 183: 3597-3605.

Tournu, H., Fiori, A., and Van Dijck, P. 2013. Relevance of trehalose in pathogenicity: Some general rules, yet many exceptions. PLoS Pathog. 9:e1003447.

Tran, T. M., MacIntyre, A., Hawes, M., and Allen, C. 2016. Escaping underground Nets: Extracellular DNases degrade plant extracellular traps and contribute to virulence of the plant pathogenic bacterium Ralstonia solanacearum. PLoS Pathog. 12:e1005686.

Tran, T. M., MacIntyre, A., Khokhani, D., Hawes, M., and Allen, C. 2016 Extracellular DNases of Ralstonia solanacearum modulate biofilms and facilitate bacterial wilt virulence. Environ. Microbiol. 18:4103-4117.

van Elsas, J. D., Kastelein, P., de Vries, P. M., and van Overbeek, L. S. 2001. Effects of ecological factors on the survival and physiology of Ralstonia solanacearum bv. 2 in irrigation water. Can. J. Microbiol. 47:842-854.

Vasse, J., Frey, P., and Trigalet, A. 1995. Microscopic studies of intercellular infection and protoxylem invasion of tomato roots by Pseudomonas solanacearum. Mol. Plant-Microbe Interact. 8:241-251.

Wu, M. C., Lin, T. L., Hsieh, P. F., Yang, H. C., and Wang, J. T. 2011 Isolation of genes involved in biofilm formation of a Klebsiella pneumoniae strain causing pyogenic liver abscess. PLoS One 6:e23500.

Ximénez-Embún, M. G., Ortego, F., and Castañera, P. 2016. Droughtstressed tomato plants trigger bottom-up effects on the invasive Tetranychus evansi. PLoS One 11:e0145275.

Yadeta, K. A., and Thomma, B. P. H. J. 2013. The xylem as battleground for plant hosts and vascular wilt pathogens. Front. Plant Sci. 4:97.

Yao, J., and Allen, C. 2006. Chemotaxis is required for virulence and competitive fitness of the bacterial wilt pathogen Ralstonia solanacearum. J. Bacteriol. 188:3697-3708.

Yao, J., and Allen, C. 2007. The plant pathogen Ralstonia solanacearum needs aerotaxis for normal biofilm formation and interactions with its tomato host. J. Bacteriol. 189:6415-6424. 